\title{
Burnout among pediatric residents and junior consultants working at a tertiary care hospital
}

\author{
Attia Bari', Rizwan Kamran², Farah Haroon ${ }^{3}$, Iqbal Bano ${ }^{4}$
}

\begin{abstract}
Objective: To determine the burnout among postgraduate residents' and junior consultants in a tertiary care hospital.

Methods: This cross-sectional study was conducted among the postgraduate residents (PGR) and junior consultants (JC) working at The Children's Hospital Lahore in 2018. Participants were asked to complete Copenhagen Burnout Inventory questionnaire about burnout on 5 point Likert scale. '100 (always), 75 (often), 50 (sometimes), 25 (seldom) and 0 (never/almost never or according to intensity ranging from 'a very low degree' to 'to a very high degree'. Data was analyzed using SPSS version 22 . Three questions were added related to hospital factors but scored separately. Students t-test and chi square test were used to compare the burnout.

Results: A total of 227 participants including 177 PGR and $50 \mathrm{JC}$ completed the questionnaire with a response rate of $84 \%$ and $86 \%$ respectively. There was a female predominance, 140 participants $(61.7 \%)$ were female. Majority was from pediatric medicine $173(76.2 \%)$. The mean personal and work relatedburnout was high among PGRs as compared to JCs $(18.68 \pm 5.01$ vs $16.62 \pm 4.57)(\mathrm{p}=0.008)$ and $(21.14 \pm 5.57$ vs. $18.56 \pm 5.52)(p=0.004)$ respectively. Similarly, there was significantly more burnout among pediatric medicine study participants as compared to surgery and diagnostic in all domains (personal $B O ; p=0.030$, work-related BO; $\mathrm{p}=0.021$, patient related $\mathrm{BO} ; 0.033$ and hospital related $\mathrm{BO} ; 0.001$ ). No difference was noted based on gender and year of training.

Conclusion: Tertiary care hospital postgraduate residents and junior consultants face moderate burnout. Postgraduate residents had significantly more burnout as compared to junior consultants and majority were from pediatric medicine.
\end{abstract}

KEYWORDS: Burnout, resident, Patient, Healthcare, Questionnaire, Copenhagen Burnout Inventory.

doi: https://doi.org/10.12669/pjms.35.1.43

How to cite this:

Bari A, Kamran R, Haroon F, Bano I. Burnout among pediatric residents and junior consultants working at a tertiary care hospital. Pak J Med Sci. 2019;35(1):45-49. doi: https://doi.org/10.12669/pjms.35.1.43

This is an Open Access article distributed under the terms of the Creative Commons Attribution License (http://creativecommons.org/licenses/by/3.0), which permits unrestricted use, distribution, and reproduction in any medium, provided the original work is properly cited.

1. Attia Bari, MBBS, D.C.H, M.C.P.S, F.C.P.S., MHPE Associate Professor

2. Rizwana Kamran, MBBS, MHPE. Assistant Professor,

CMH Lahore Medical College \& Institute of Dentistry (NUMS).

3. Farah Haroon, MBBS, FCPS (Paediatric Medicine), FCPS (Neonatology)

Associate Professor Pediatric Neonatology,

4. Iqbal Bano, MBBS, F.C.P.S

Associate Professor,

1,3,4: Department of Paediatric Medicine,

The Children's Hospital and The Institute of Child Health, Lahore, Pakistan.

Correspondence:

Dr. Attia Bari, MBBS, DCH, MCPS, FCPS, MHPE E-mail: drattiabari@gmail.com

* Received for Publication:

August 13, 2018

* Revision Received:

November 16, 2018

* Revision Accepted:

\section{INTRODUCTION}

Burnout is prevalent amongst workers involved in helping professions like teachers, psychologists and physicians. ${ }^{1}$ It is commonly high among healthcare professionals. ${ }^{2}$ Burnout is a state of chronic stress causing various levels of physical and psychological exhaustion suffered by the individual. ${ }^{3}$ In 1981, Maslach and Jackson defined burnout as a three-dimensional syndrome of emotional exhaustion, depersonalization, and lack of personal accomplishment. ${ }^{4}$

Persistent distress and tension among individuals are the root causes of emotional exhaustion and leads to occupational inefficiency, dissatisfaction 
and frustration. Depersonalization occurs when doctors develop a negative environment and attitude towards their patients or colleagues, leading to the deterioration of the social climate at their workplace. Inefficiency and lack of personal accomplishment is depicted by the inability of person to do his job responsibilities and resulting detachment and untimely retirement. ${ }^{4}$

Several studies revealed a high level of burnout among residents, junior doctors and fellows particularly in their early training phase. Long working duration, demanding jobs and difficult working environments in organizations can cause physical and emotional distress. Moreover, burnout among residents can affect the delivery of safe care, satisfaction of patients and physicians' emotional wellbeing. ${ }^{5,6}$ Many questionnaires have been developed to measure burnout namely: the Maslach Burnout Inventory, ${ }^{4}$ Copenhagen Burnout Inventory $(\mathrm{CBI})^{3}$ and Oldenburg Burnout Inventory. ${ }^{7}$

Pediatric specialty is a very demanding field and a full-time emergency. In Pakistan, very little literature is published with an outcome of physicians' stress and job satisfaction particularly of pediatric specialty. We planned this study to measure the level of burnout among pediatric PGRs and JCs of senior registrar (SR) level, and also to find the contributing elements of high burnout. The study assists us to identify and take measures to resolve the issues regarding burnout if it is present and improve quality of life of pediatric residents and ultimately safe patient care.

\section{METHODS}

This study was conducted at The Children's Hospital and The Institute of Child Health (ICH) Lahore, a largest Pediatric tertiary care hospital in Pakistan. PGRs who joined ICH at least six months prior to the survey and SR/JC working at ICH were included. After taking permission from the hospital ethical committee a voluntary and anonymous questionnaire was distributed to PGRs and JCs.

Burnout was assessed with CBI; a selfadministered, pre-tested and pre-validated tool adapted from the one developed by Maslach. The reliability coefficient of the questionnaire is $0.87 .{ }^{3}$ CBI consists of 19-item questionnaire having three subscales: personal burnout (6 items), work burnout (7 items) and patient burnout (6 items) scored on a 5-point Likert scale according to the frequency with which the respondent feels a particular way in relation to his or her work. Twelve items have responses of frequency ranging from; 100 (always),
75 (often), 50 (sometimes), 25 (seldom) and 0 (never/ almost never). Seven items use response categories according to intensity ranging from 'a very low degree' to 'to a very high degree'. Item number 10 was negative statement and was reverse coded.

Being a tertiary care referral hospital of a developing country, there are few other factors which may be a cause of burnout among PGRs and JCs so three more questions of associated hospital related factors were added as suggested by hospital ethical committee. These questions were scored separately.

Frequencies and descriptive statistics were examined for each variable. Statistical comparisons were performed between the "burned out" PGR/JC and the "non-burned out" PGR/JC concerning demographic characteristics. Dichotomous variables were compared with the chi-square test. Statistical significance was considered as $p<0.05$. In order to look in to each dimension of burnout separately comparisons of each burnout dimension's mean score for type of specialty was tested by student's $t$-test.

\section{RESULTS}

In our study 227 participants (177 PGR and 50 JC) from three pediatric subspecialties of medicine, surgery and diagnostic (radiology and pathology) were included. Questionnaire was distributed to 210 PGRs and $58 \mathrm{JC}$ with a response rate of $84 \%$ and $86 \%$ respectively. There was a female predominance $140(61.7 \%)$ and majority were from pediatric medicine 173 (76.2\%). Demographic characteristics for the study participants are shown in the Table-I. The participant's individual domain burnout scores

Table-I: Characteristics of residents and junior consultants.

\begin{tabular}{lcc}
\hline Characteristic & $\begin{array}{c}\text { Postgraduate } \\
\text { Resident }(n=177)\end{array}$ & $\begin{array}{c}\text { Senior } \\
\text { Registrar } \\
(n=50)\end{array}$ \\
\hline Age & $25-30$ years & $30-40$ years \\
Gender & $66(37.2 \%)$ & $21(42 \%)$ \\
Males & $111(62.7 \%)$ & $29(58 \%)$ \\
Females & & \\
Specialty & $136(76.9 \%)$ & $37(74 \%)$ \\
Pediatric Medicine & $21(11.8 \%)$ & $06(12 \%)$ \\
Pediatric Surgery & $20(11.3 \%)$ & $07(14 \%)$ \\
Pediatric Diagnostic & & \\
Year of postgraduate & & \\
$\quad$ residency & $64(36.2 \%)$ & \\
$1^{\text {st }}$ Year & $44(24.9 \%)$ & \\
$2^{\text {nd }}$ Year & $36(20.3 \%)$ & \\
$3^{\text {rd }}$ Year & $19(10.7 \%)$ & \\
$4^{\text {th }}$ Year & $14(07.9 \%)$ & \\
Training complete & & \\
\hline
\end{tabular}


Table-II: Items and Mean/SD of PGRs and Junior Consultants score in CBI Scale.

\begin{tabular}{|c|c|c|c|c|c|}
\hline Response category of Burnout & $\begin{array}{c}\text { Always } \\
\text { or To a very } \\
\text { high degree } \\
\text { (Score 100\%) }\end{array}$ & $\begin{array}{l}\text { Often or To } \\
\text { a high degree } \\
\text { (Score } 75 \% \text { ) }\end{array}$ & $\begin{array}{l}\text { Some-times } \\
\text { or somewhat } \\
\text { (Score } 50 \%)\end{array}$ & $\begin{array}{l}\text { Seldom or To } \\
\text { a low degree } \\
\text { (Score } 25 \% \text { ) }\end{array}$ & $\begin{array}{l}\text { Never almost } \\
\text { never or to } \\
\text { a very low } \\
\text { degree } \\
\text { (Score } 0 \% \text { ) }\end{array}$ \\
\hline Personal burnout & $n(\%)$ & $n(\%)$ & $n(\%)$ & $n(\%)$ & $n(\%)$ \\
\hline How often do you feel tired? a & $40(17.6)$ & $79(34.8)$ & $67(29.5)$ & $41(18.1)$ & \\
\hline How often are you physically exhausted? a & $31(13.7)$ & $75(33)$ & $69(30.4)$ & $47(20.7)$ & $05(2.2)$ \\
\hline How often are you emotionally exhausted? a & $28(12.3)$ & $66(29.1)$ & $67(29.5)$ & $59(26)$ & $7(3.1)$ \\
\hline $\begin{array}{l}\text { How often do you think: "I can't take it } \\
\text { anymore" a }\end{array}$ & $26(11.5)$ & $31(13.7)$ & $60(26.4)$ & $67(29.5)$ & $43(18.9)$ \\
\hline How often do you feel worn out? ${ }^{a}$ & $14(6.2)$ & $43(18.9)$ & $74(32.6)$ & $78(34.4)$ & $18(7.9)$ \\
\hline $\begin{array}{l}\text { How often do you feel weak and susceptible } \\
\text { to illness? a }\end{array}$ & $12(5.3)$ & $41(18.1)$ & $64(28.2)$ & $76(33.5)$ & $32(14.1)$ \\
\hline \multicolumn{6}{|l|}{ Work-related burnout } \\
\hline $\begin{array}{l}\text { Do you feel worn out at the end of the } \\
\text { working day? a }\end{array}$ & $34(15)$ & $71(31.3)$ & $71(31.3)$ & 40 (17.6) & $11(4.8)$ \\
\hline $\begin{array}{l}\text { Are you exhausted in the morning at the } \\
\text { thought of another day at work? }{ }^{a}\end{array}$ & $30(13.2)$ & $45(19.8)$ & $59(26)$ & $63(27.8)$ & $30(13.2)$ \\
\hline $\begin{array}{l}\text { Do you feel that every working hour is tiring } \\
\text { for you? a }\end{array}$ & $14(6.2)$ & $30(13.2)$ & $48(21.1)$ & $87(38.3)$ & $48(21.1)$ \\
\hline $\begin{array}{l}\text { Do you have enough energy for family and } \\
\text { friends during leisure time? (Reverse coding) }\end{array}$ & $18(7.9)$ & $59(26)$ & $67(29.5)$ & $52(22.9)$ & $31(13.7)$ \\
\hline Is your work emotionally exhausting? ${ }^{\mathrm{b}}$ & $31(13.7)$ & $58(25.6)$ & $66(29.1)$ & $51(22.5)$ & $21(9.3)$ \\
\hline Does your work frustrate you? ${ }^{\mathrm{b}}$ & $20(8.8)$ & $55(24.2)$ & $44(19.4)$ & $69(30.4)$ & $39(17.2)$ \\
\hline Do you feel burnout because of your work? ${ }^{b}$ & $22(9.7)$ & $50(22)$ & $65(28.6)$ & $61(26.9)$ & $29(12.8)$ \\
\hline \multicolumn{6}{|l|}{ Patient-related burnout } \\
\hline Do you find it hard to work with patients? ${ }^{b}$ & $12(5.3)$ & $29(12.8)$ & $57(25.1)$ & $80(35.2)$ & 49 (21.6) \\
\hline $\begin{array}{l}\text { Does it drain your energy to work with } \\
\text { patients? }{ }^{b}\end{array}$ & $11(4.80)$ & $43(18.9)$ & $59(26)$ & $73(32.2)$ & $41(18.1)$ \\
\hline $\begin{array}{l}\text { Do you find it frustrating to work with } \\
\text { patients? }{ }^{b}\end{array}$ & $10(4.4)$ & $24(10.6)$ & $52(22.9)$ & $80(35.2)$ & $61(26.9)$ \\
\hline $\begin{array}{l}\text { Do you feel that you give more than you get } \\
\text { back when you work with patients? }{ }^{b}\end{array}$ & $26(11.5)$ & $44(19.4)$ & $66(29.1)$ & $64(28.2)$ & $27(11.9)$ \\
\hline Are you tired of working with patients? ${ }^{a}$ & $14(6.2)$ & $18(7.9)$ & $50(22)$ & $85(37.4)$ & $60(26.4)$ \\
\hline $\begin{array}{l}\text { Do you sometimes wonder how long you will } \\
\text { be able to continue working with patients? }\end{array}$ & $17(7.5)$ & $30(13.2)$ & $50(22)$ & $76(33.5)$ & $54(23.8)$ \\
\hline \multicolumn{6}{|l|}{ Hospital/Logistics-related burnout } \\
\hline $\begin{array}{l}\text { Do you feel frustrated due to lack of proper } \\
\text { laboratory backup? a }\end{array}$ & $88(38.8)$ & $62(27.3)$ & $41(18.1)$ & $30(13.2)$ & $6(2.6)$ \\
\hline $\begin{array}{l}\text { Do you feel frustrated due to patient outcome } \\
\text { related satisfaction? }{ }^{\mathrm{b}}\end{array}$ & $32(14.1)$ & $79(34.8)$ & $74(32.6)$ & $36(15.9)$ & $6(2.6)$ \\
\hline $\begin{array}{l}\text { Do you feel frustrated due to huge number of } \\
\text { patients which you have to see? }{ }^{a}\end{array}$ & $69(30.4)$ & $56(24.7)$ & $63(27.8)$ & $28(12.3)$ & $11(4.4)$ \\
\hline
\end{tabular}

${ }^{a}$ Always, often, sometimes, seldom, never/ almost never (scoring: 100\%, 75\%, 50\%, 25\%, 0\%)

${ }^{\mathrm{b}} \mathrm{To}$ a very high degree, to a high degree, somewhat, to a low degree, to a very low degree. 
Attia Bari et al.

Table-III: Individual domains burnout score of the study participants.

\begin{tabular}{lcccc}
\hline Burnout Key Domains & Item number & $\begin{array}{c}\text { Postgraduate Residents } \\
\text { Mean/SD }\end{array}$ & $\begin{array}{c}\text { Junior Consultants } \\
\text { Mean/SD }\end{array}$ & $p$-value \\
\hline Personal burnout & $1-6$ & $18.68 \pm 5.01$ & $16.62 \pm 4.57$ & 0.008 \\
Work-related burnout & $7-13$ & $21.14 \pm 5.57$ & $18.56 \pm 5.52$ & 0.004 \\
Client-related burnout & $14-19$ & $15.36 \pm 5.64$ & $13.86 \pm 4.89$ & 0.089 \\
Hospital/ Logistics-related burnout & $20-22$ & $11.07 \pm 2.70$ & $10.36 \pm 2.94$ & 0.108 \\
\hline
\end{tabular}

are shown in Table-II. These scores provide a view of the burnout among the PGRs and JC.

The mean personal $\mathrm{BO}$ was high among PGRs as compared to JC $(p=0.008)$ and work relatedburnout $(p=0.004)$ shown in Table-III. Similarly, there was significantly more burnout among pediatric medicine study participants as compared to surgery and diagnostic in all domains (personal $\mathrm{BO} ; \mathrm{p}=0.030$, work-related $\mathrm{BO} ; \mathrm{p}=0.021$, patientrelated $\mathrm{BO} ; 0.033$ and hospital-related $\mathrm{BO} ; 0.001$ ). There were only three items which showed statistically significant difference between PGR and JC (Table-IV).

\section{DISCUSSION}

Globally burnout is generally high among doctors with varying rates by gender, medical specialty and career stage. PGRs are continually challenged to be on the forefront of patient interaction. Intense work demands in residency predispose PGR and high job responsibility on faculty results in burnout. We used CBI and preferred it over the more popular Maslach Burnout Inventory (MBI) because it is available free and had similar properties.

Overall prevalence of a particular condition can be relied upon with a good response rate. Our high response rate is consistent with a longitudinal study published in Ochsner Journal. ${ }^{8}$ A lower response rate $68 \%$ and $50 \%$ were shown in studies from Spain and UK respectively. ${ }^{9,10}$ A study from Pakistan using CBI on medical students showed $35.9 \%$ of students confirmed high levels of burnout. ${ }^{11}$ Similarly a review article from China showed overall prevalence of burnout ranging from 66.5 to $87.8 \%$ and burnout was higher among doctors working in tertiary care hospitals and who had long working hours of over $40 \mathrm{~h} /$ week. $^{12}$ A research from a tertiary care hospital showed contradictory results in which majority had low burn out and $11 \%$ were having moderate and only $1.4 \%$ had high burnout. ${ }^{13}$ A study from Spain showed that $40 \%$ of PGRs had burnout by one year of their residency training. ${ }^{9}$ Our results showed no difference in burnout when different years of training are compared.

In our study, overall personal burnout was quite high as almost $65 \%$ of PGR and JC had scores in the range of $50-75 \%$. Our results are consistent with a study from India in which CBI was used and more than half residents showed high scores of personal burnout domain. ${ }^{14}$ Similar results are shown in a research from Saudi Arabia tertiary care hospital in which burnout syndrome was identified in a high proportion $(88.5 \%)$ of the respondents. ${ }^{15}$ Being the largest tertiary care referral center, the reason

Table-IV: Items with Significant Differences between PGRs and Junior Consultants

\begin{tabular}{|c|c|c|c|c|c|c|}
\hline Participants & $\begin{array}{c}\text { Never almost never } \\
\text { or to a very low } \\
\text { degree (Score } 0 \%)\end{array}$ & $\begin{array}{l}\text { Seldom or to } \\
\text { a low degree } \\
\text { (Score } 25 \%)\end{array}$ & $\begin{array}{c}\text { Some-times or } \\
\text { somewhat } \\
(\text { Score } 50 \%)\end{array}$ & $\begin{array}{l}\text { Often or to a } \\
\text { high degree } \\
\text { (Score } 75 \%)\end{array}$ & $\begin{array}{c}\text { Always or to a } \\
\text { very high degree } \\
\text { (Score } 100 \%)\end{array}$ & p-value \\
\hline \multicolumn{7}{|c|}{ Personal BO: How often do you feel tired? } \\
\hline PGR & & $33(18.6 \%)$ & $41(23.2 \%)$ & $67(37.9 \%)$ & $36(20.3 \%)$ & \multirow{2}{*}{0.001} \\
\hline Junior Consultant & & $08(16 \%)$ & $26(52 \%)$ & $12(24 \%)$ & $04(8 \%)$ & \\
\hline \multicolumn{7}{|c|}{ Personal BO: How often are you physically exhausted? } \\
\hline PGR & $5(2.8 \%)$ & $28(15.8 \%)$ & $53(29.9 \%)$ & $62(35 \%)$ & $29(16.4 \%)$ & \multirow{2}{*}{0.003} \\
\hline Junior Consultant & $0(0 \%)$ & $19(38 \%)$ & $16(32 \%)$ & $13(26 \%)$ & $02(04 \%)$ & \\
\hline \multicolumn{7}{|c|}{ Work related BO: Do you feel worn out at the end of the working day? } \\
\hline PGR & $9(5.1 \%)$ & $27(15.3 \%)$ & $48(27 \%)$ & $63(35.6 \%)$ & $30(17 \%)$ & \multirow{2}{*}{0.007} \\
\hline Junior Consultant & $2(4 \%)$ & $13(26 \%)$ & $23(46 \%)$ & $08(16 \%)$ & $04(8 \%)$ & \\
\hline
\end{tabular}


of high personal, work-related and patient-related burnout among PGRs is the changing patient profile which PGRs face while their rotation to different wards.

Multiple factors like social or demographic including gender and age can be indirectly responsible for the job-related burnout. We did not find any difference in burnout score based on gender and similar results narrated in a study from Pakistan published in PJMHS that there was no association of gender with the burnout ( $p$-value 0.782) ${ }^{16}$ But conflicting results are shown in another study from Karachi which showed that females doctors had higher burnout scores than male counterparts. ${ }^{17}$ The pediatric medicine residents have more interaction with patients that might be the cause for higher patient-related burnout when compared with diagnostic residents.

Limitations: Our study is a cross-sectional survey and cannot explain the variation of burnout which can happen over time. Moreover, this is a single centered study limiting the generalization of our results to postgraduate residents and junior consultants of other institutes including both public and private sector.

\section{CONCLUSION}

Burnout is a common problem among postgraduate residents and junior consultants. The high prevalence of burnout demonstrates the need for appropriate strategies to prevent adverse effects on doctors' quality of life and on the quality of care patients receive.

\section{Conflict of interest: None.}

\section{Source of funding: None.}

\section{REFERENCES}

1. Lemaire JB, Wallace JE. Burnout among doctors. BMJ. 2017;358:j3360. doi: 10.1136/BMJ.J3360

2. Pereira-Lima K, Loureiro SR. Burnout, anxiety, depression, and social skills in medical residents. Psychol Health Med. 2015;20(3):353-362. doi: 10.1080/13548506.2014.936889.

3. Kristensen TS, Borritz M, Villadsen E, Christensen KB. The Copenhagen Burnout Inventory: A new tool for the assessment of burnout. Work Stress.2005;19(3):192-207. doi: $10.1080 / 02678370500297720$.

4. Maslach C, Leiter MP. Early predictors of job burnout and engagement. J J Appl Psychol. 2008;93(3):498-512. doi: 10.1037/0021-9010.93.3.498.

5. Waheed K, Liaqat N, Ejaz S, Khanum A, Ijaz S, Butt A, et al. Burnout among gynaecological residents in lahore, Pakistan: A cross-sectional survey. J Pak Med Assoc. 2017;67(9):1318-1322.
6. Dyrbye LN, West CP, Satele D, Boone S, Tan L, Sloan J, et al. Burnout Among U.S. Medical Students, Residents, and Early Career Physicians Relative to the General U.S. Population. Acad Med. 2014;89(3):443-451. doi: 10.1097/ ACM.0000000000000134.

7. Demerouti E, Mostert K, Bakker AB. Burnout and Work Engagement: A Thorough Investigation of the Independency of Both Constructs. J Occup Health Psychol. 2010;15(3):209222. doi: $10.1037 / \mathrm{a} 0019408$.

8. Parr JM, Pinto N, Hanson M, Meehan A, Moore PT. Medical Graduates, Tertiary Hospitals, and Burnout: A Longitudinal Cohort Study. Ochsner J. 2016;16(1):22-26.

9. Navines R, Olive V, Ariz J, Lopez J, Tortajada M, Varela P, et al. Stress and Burnout During the First Year of Residence Training in a University Teaching Hospital: Preliminary Date. Dual Diagnosis. 2016;1(3):15-18. doi: 10.21767/24725048.100017

10. Monrouxe L V, Bullock A, Tseng H-M, Wells SE. Association of professional identity, gender, team understanding, anxiety and workplace learning alignment with burnout in junior doctors: a longitudinal cohort study. BMJ. 2017;7(12):e017942. doi: 10.1136/bmjopen-2017-017942.

11. Muzafar Y, Khan HH, Ashraf H, Hussain W, Sajid H, Tahir $\mathrm{M}$, et al. Burnout and its Associated Factors in Medical Students of Lahore, Pakistan. Cureus. 2015;7(11):1-12. doi: 10.7759 /cureus.390.

12. Lo D, Wu F, Chan M, Chu R, Li D. A systematic review of burnout among doctors in China: A cultural perspective. Asia Pac Fam Med. 2018;17(1):1-13. doi: 10.1186/s12930-0180040-3.

13. Joena MV, Pragasam RAX. Prevalence and factors affecting burnout among medical professionals - A cross sectional study from a tertiary care teaching hospital. Int Arch Integr Med. 2016;3(10):62-69.

14. Ratnakaran B, Prabhakaran A, Karunakaran V. Prevalence of burnout and its correlates among residents in a tertiary medical center in Kerala, India: A cross-sectional study. J Postgrad Med. 2016;62(3):157-161.

15. Agha A, Mordy A, Anwar E, Saleh N, Rashid I, Saeed M. Burnout among middle-grade doctors of tertiary care hospital in Saudi Arabia. Work. 2015;51(4):839-847. doi: 10.3233/WOR-141898.

16. Aftab H, Akram MA, Fatima A, Rehman F, Zeeshan M. Physician's Burnout Rate at King Edward Medical University: A cross sectional survey. PJMHS. 2016;10(4):1207-1209.

17. Das K, Subhani MH, Ramesh P, Maria A, Hashmi S. Factors Associated with Medical Residents Burnout in Tertiary Care Hospital in Karachi. APMC. 2017;11(2):122-125.

\section{Authors Contribution:}

AB: Main author, conceived idea, manuscript writing.

RK: Literature searching, contributed in manuscript writing, proof reading.

FH: Data collection.

IB: Critical review. 